\title{
A Closed Operating Mechanism for the Accountability System of Administrative Decision-making Errors
}

\author{
Yao-kui Li \\ School of Economics and Management \\ Taishan University \\ Taian, China
}

\begin{abstract}
The accountability of administrative decisionmaking errors is mostly in the state of "lack of system" or "lack of dynamic" in reality. This results in more decision-making errors. Normalized decision-making management is an effective way to reduce the administrative decision-making errors. This article adopted closed system research method to establish a closed operating mechanism for the accountability system of administrative decision-making errors. We built the accountability system by these subsystems: the routine inspection subsystem of administrative decision-making errors, the investigating subsystem of the accountability, the executive subsystem of the accountability, the monitoring and feedback subsystem of the accountability. These subsystems form a closed operating loop together; each subsystem is relatively independent and responsible for each other. The closed operating mechanism for the accountability system of administrative decision-making errors will help to get rid of the phenomenon of supervision paradox in the administration, and it will certainly help to minimize the administrative decision-making errors.
\end{abstract}

Keywords-Administrative decision-making; Decision-making error; Accountability system; Closed operating mechanism

\section{INTRODUCTION}

In the administrative practice, decision-making errors often occur because of the influence of the decision-makers' decision-making level, the subjective reasons of the decisionmakers, the imperfection of the decision-making system, the decision-making conditions and so on. What is more worthy of our attention is that the accountability of the decision-making errors is mostly in the state of "lack of system" or" lack of dynamic mechanism" in reality. It is especially obvious that the relevant personnel turn a blind eye to the decision-making errors, or they find the errors but they don't investigate, or they investigate but there is no result. These phenomena often result in more decision-making errors. As most of the administrative decisions are related to the life of the country and the people, the administrative decision-making errors often damage the interests of the public, bruise the creativity of the public, affect the relationship between the government and the public, damage the image of the government, and bring many problems to the political, economic and social life. Therefore, it is an urgent task to establish and improve the accountability system for administrative decision-making errors. This article will focus on the actual operation from the perspective of "system" and "dynamic mechanism", and will discuss the implementation of the system from the dynamic level.

In the book of Organizations in Action (New York: McGraw-Hill, 1967), James Thompson proposes a closed system research method for the study of complex organizations. This method mainly focuses on the efficiency of achieving the goal. It insists on using organizational resources in a practical way, making every part of the organization conform by the "logic" of the system, and reducing the uncertainty of the environment through the control mechanism [1]. Professor Ming-jieRui talks about the designing art of organization in the book of Management: Modern View: "The closure of organizational structure is an important factor for improving the organizational structure. Any organization system should not only maintain the necessary connection with the outside, that is, output and input, but also form a closed loop inside the organization system. Only the closed loop relationship can form the forces of mutual restriction and interaction, and the division of labor could act in accordance with a scientific track. This helps to achieve the effective management [2]."

A closed operating mechanism should be established for the accountability system of administrative decision-making errors. In the process of carrying out the accountability of administrative decision-making errors, each segment of the accountability system should be connected, and they should form a closed operating loop based on their job responsibilities. Meanwhile, each participating body of the accountability system should also form a closed operating loop. We can build the accountability mechanism by these subsystems: the routine inspection subsystem of the administrative decision-making errors, the investigating subsystem of the accountability, the executive subsystem of the accountability, the monitoring and feedback subsystem of the accountability. These subsystems form a closed operating loop together, each subsystem is relatively independent, and they are mutually responsible.

The routine inspection subsystem of the administrative decision-making errors should notify the investigating subsystem of the administrative decision-making errors about the routine inspection; the investigating subsystem of the 
administrative decision-making errors should report the investigation result to the executive subsystem of the accountability, and the executive subsystem of the accountability should inform the monitoring and feedback subsystem of the implementation situation of the responsibility, and the monitoring and feedback subsystem of the accountability should inform the routine inspection subsystem and the victims of misdecision of the implementation situation. A closed operating mechanism comes out.

\section{THE ROUTINE INSPECTION AND SUPERVISION SUBSYSTEM OF THE ADMINISTRATIVE DECISION-MAKING ERRORS}

This subsystem is responsible for routine inspection and supervision of the administrative decisions, exercises the power of inspection and supervision, and accepts the inquiry from the Congress or the relevant departments about their omission. The inspection and supervision on the decision-making should be routine, that is to say, the decision-making status of all the administrative organs should be checked every other period. Once the administrative decision-making errors are found out, they should be dealt with in time.

If the error is serious, the decision-makers should be investigated and dealt with by the investigating subsystem. If the error is not serious, the decision-makers should be admonished. At the same time, in order to make the administrative decision better and better, the relevant departments should build up the evaluation system about the status of the routine decisions so as to reward the good decisions and reduce the bad decisions, taking the masses' satisfaction as the basic standard.

\section{INFORMATION COLLECTION AND RECOGNITION SUBSYSTEM OF THE ADMINISTRATIVE DECISION-MAKING ERRORS}

This subsystem actually exercises the power of investigation. Its function is to collect the information about the administrative decision-making errors and make a good analysis about the errors. It is in charge of the early basic investigating affairs of the decision-making errors. It makes an investigation and analysis on the reasons for the errors, the scope of the errors and the consequences of the errors. Meanwhile, this subsystem should record the results of the investigation and analysis and the relevant personnel should sign the memorandum. And then, this subsystem should pass the results of the investigation and analysis to the executive subsystem of the accountability.

Specifically, the administrative decision-making errors should be investigated and analyzed from the following aspects.

\section{A. Defining the Scope of the Administrative Decision-making Errors}

Administrative decision-making is an important content of the administrative activities, and it even involves every field of the society. When decision-making errors occur, the scope of the impact of different decision-making errors will be different. Therefore, the scope of the decision-making errors should be considered as a dimension of the accountability.

Administration refers to the activities of the administrative organs in managing state affairs, public affairs and the internal affairs of the administrative organs according to the law [3]. According to this definition, administrative decisions involve state affairs, public affairs and the internal affairs of administrative organs. Obviously, the importance and reach of these affairs are different. In the analysis on decision-making errors, we should take into account the nature and scope of the decision itself. If the national interests and national dignity are damaged because of a decision-making error, or the decisionmaking error brings damage to the public interests and results in the dissatisfaction of the masses, the relevant decisionmakers should be held accountable for the error strictly. The decision-making errors of the internal affairs of the administrative organs have smaller scope, and the loss of interests mainly involves the staff of the unit. The accountability should be carried out on the basis of the internal management regulations of the administrative organs.

\section{B. Distinguishing the Controllable Factors and Uncontrollable Factors}

When the relevant investigators investigate the factors that cause a decision-making error, it is necessary to distinguish whether the decision-makers can properly control these factors and how much they can control these factors when they make the decision. If the factors are controllable, and it is the decision-makers' negligence and paralysis that lead to the error, the decision-makers must be held accountable for this kind of decision-making error according to the scope caused by the error. If a decision-making error is mainly caused by uncontrollable or less controllable factors, the decision-makers mustn't be held accountable for this kind of decision-making error. Of course, in order to prevent the investigators from monopolizing and distorting the information about the decision-making errors, an information publicity system of the decision-making errors should be established to accompany with the accountability. In a word, the accountability is mainly used to prosecute the decision-making errors caused by the decision-makers' negligence and paralysis to the controllable factors. It is obviously unfair and undesirable to prosecute the decision-making errors caused by the uncontrollable factors. 


\section{The Definition of the Responsibility of Decision-making Errors in Different Decision-making Methods}

The individual decision-maker is held accountable for the decision-making errors caused by individual decision-making. The decision-making errors caused by the collective leadership decision-making should be analyzed from the following angles: firstly, the relevant departments should analyze the decisionmaking tendencies of all the decision-makers according to the records of the decision meetings, and then define the responsibility of decision-making errors according to the decision-making tendency. Therefore, the record system of the decision-meeting should be perfected. Once a decision-making error occurs, it is possible to carry out the investigation and forensics according to the record of decision-making. This helps to promote the seriousness of the administrative decision and reduce the decision-making errors caused by the subjective factors. The disadvantage of this method is that the decisionmakers may not express their opinions for fear of decisionmaking errors. Decisions on such conditions should be conducted through consultation, argumentation, referendum and publicity according to the nature and types of the affairs. Secondly, the relevant departments should define the responsible person for the decision-making errors. In the routine decision-making practice, the chief leader and the vice leader in charge of the affairs often play major roles in the collective decision-making. They are not only the promoters of decision-making but also the main undertakers of decisionmaking errors. Therefore, we should establish and improve the responsibility system for decision-making errors, clearing the responsibility for the main decision-makers.

\section{Analyzing the Decision Motivation of Decision-makers}

The decision-making motivation of the decision makers will have a great impact on the decision results. For example, the decision-makers may have rent-seeking psychology in the decision-making. Whether recessive rent-seeking or explicit rent-seeking will have adverse effects on decision-making. This kind of decision-making error should be strictly prosecuted. And for example, different political interests groups in the decision-making group intentionally mislead the decisions because of bad motivation of mutual attack, which leads to decision-making errors. Decision-making errors of this kind should be strictly prosecuted according to the minutes of the decision meeting. Sometimes, non-adverse motivation can also lead to decision-making errors. For example, decisionmakers are driven by their superior leadership, and the superior leadership is driven by his own benefit. For another example, some decision-makers have no innovation in their work. They apply superior documents mechanically and apply the experience of other units or departments regardless of the local conditions. All these can lead to the decision-making errors. In short, when the relevant investigators analyze the source of the decision-making errors, they must analyze the decision makers' motivations.

\section{E. Analyzing the Time of the Decision-making}

Administrative decisions should be timely, and slow decisions are essentially decision-making errors. When a decision needs to be made, it must be made quickly. Otherwise, conditions will become worse and worse. The decision-makers must be held accountable for this kind of decision-making error according to the relevant regulations and laws about their duties.

\section{F. Analyzing each segment of decision-making process}

Once a decision-making error occurs, the investigators should start investigation and analysis from each segment of the decision-making process. They should investigate the decision-making information system, the consultation system of the decision-making, the central system of the decisionmaking, the executive system of the decision, and the feedback system of the decision and so on, and find out the possible factors that cause the error in the decision-making process.

\section{THE EXECUTIVE SUbSYSTEM OF THE ACCOUNTABILITY OF THE ADMINISTRATIVE DECISION-MAKING ERRORS}

This subsystem exercises the power of disposal and execution. It is still difficult to execute the accountability for administrative decision-making errors in the current administrative practice. The first reason is that the long-effect mechanism of accountability hasn't yet formed. The second is that the executive bodies of administrative decision are all the executors of the administrative power. Therefore, the executive bodies of the accountability for administrative decision-making errors must have greater political authority and can be deterrent to those who fail in decision-making. At present, Party Committees, Discipline Inspection Committees, Supervision Committees and People's Congresses of all levels in China are the appropriate executive bodies of the accountability for administrative decision-making errors.

After the investigating subsystem collects and analyzes the information about the decision-making errors, the investigators should report the results to the above executive bodies of the accountability for the administrative decision-making errors. The above executive bodies can divide the work, and they can also form a panel discussion committee. They distinguish and determine the types of the responsibility for the administrative decision-making errors. Generally speaking, the responsibility for the administrative decision-making errors mainly includes moral responsibility, political responsibility, economic responsibility and legal responsibility. Moral responsibility is a responsibility constraint based on the moral requirements recognized by the society, which is mainly manifested on the self-accusation for the administrative decision-making errors. Political responsibility means that officials should formulate policies that conform to the public opinion, while they should be condemned and punished when they fail to perform their duties well. The main manifestation is the loss of political trust [4]. Economic responsibility means that the decision-makers should give a certain proportion of compensation according to the economic losses caused by the administrative decisionmaking errors [5]. The legal liability refers to the responsibility that the decision-makers should undertake when the 
consequences of the administrative decision-making errors involve the relevant legal regulations [6].

First of all, the executive bodies of the accountability of the administrative decision-making errors should distinguish the type of the responsibility. Those who should be held accountable for their moral responsibility should be admonished. Those who should be held accountable for their political responsibility should be demoted or even dismissed from the post. Those who should be held accountable for their economic responsibility should be given economic punishment. Those who should be held accountable for their legal responsibility should be transferred to the judicial authorities. All kinds of treatment results must be publicized so as to ensure the results convenient for the public monitoring.

\section{THE MONITORING AND FEEDBACK SUBSYSTEM OF THE ACCOUNTABILITY}

This subsystem is responsible for monitoring the implementation of the accountability for the administrative decision-making errors and exercises the monitoring power. The monitoring body can be made up of Discipline Inspection Committees, Supervision Committees, People's Congress, the news media, the social intermediary organization, the civil society group, the main group of victims of the administrative decision-making errors and the other citizens with the ability to participate. Taking China as an example, Discipline Inspection Committee, Supervision Committee and People's Congress should form a special department to monitor the implementation of the accountability for the administrative decision-making errors. And of all the bodies, People's Congress should take the leading role.

And meanwhile, A return visit system for the group of victims of the administrative decision-making errors should be established to prevent the poor execution of the accountability and possible retaliation. It also helps to get rid of the phenomenon of supervision paradox inner the administration.

The monitoring and feedback subsystem of the accountability and the routine inspection subsystem, the investigating subsystem, the executive subsystem form a closed operating loop together, which helps the accountability mechanism for the administrative decision-making errors operate effectively.

\section{CONCLUSION}

The operation of the accountability mechanism for decision-making errors may encounter many difficulties and obstacles in practice. A closed operating mechanism for the accountability system of administrative decision-making errors will help to get rid of the phenomenon of supervision paradox inner the administration, and it will certainly help to reduce the administrative decision-making errors to the maximum.

\section{REFERENCES}

[1] Robert B $\cdot$ Denhardt, Public Organization Theory, (Translators: Songmao $\mathrm{Fu}, \mathrm{Li}$ Ding) Publishing House of Renmin University of China,Beijing, 2003, pp92-93. (In Chinese)

[2] Ming-jie Rui, Management: Modern View ,Publishing House of Shanghai Renmin, Shanghai, 1999, pp94-95. (In Chinese)

[3] Shu-zhang Xia, Administration Management, Publishing House of Zhongshan University, Guangzhou, 1998, p2. (In Chinese)

[4] Bang-you Xu, "On the Definition of the Responsibility of Officials' Non-autonomous Behavior", Chinese Public Administration, March, 2005, pp19-22. (In Chinese)

[5] Shufang Zhang, "Discussing the Accountability of Administrative Decision-making Errors", Journal of Soochow University (Philosophy \& Social Science Edition), December, 2013, pp61-69. (In Chinese)

[6] Lianjiang Hui, "Establishing and Improving the Legal Accountability System for Government Decision-making Errors", Journal of National School of Administration, October,2000, pp17-19. (In Chinese) 